\title{
A abordagem histórica na produção acadêmica brasileira sobre biblioteca escolar (2001-2012)
}

The historical approach of Brazilian academic production on school library (2001-2012)

\author{
Franciele Ruiz Pasquim \\ Doutoranda em Educação pela Faculdade de Filosofia e Ciências da Universidade Estadual Paulista (UNESP), \\ campus de Marília. \\ E-mail: francielepasquim@gmail.com
}

\section{Resumo}

Com o objetivo de contribuir para a produção de uma história da biblioteca escolar no Brasil, focalizam-se, neste artigo, teses e dissertações com abordagem histórica sobre o tema. Centrada em pesquisa documental e bibliográfica, desenvolvida por meio dos procedimentos de localização, recuperação, reunião, seleção e ordenação de fontes documentais, elaborou-se um instrumento de pesquisa no qual estão reunidas referências de textos acadêmicos sobre biblioteca escolar. A partir da análise da produção acadêmica sobre biblioteca escolar, entre os anos de 2001 e 2012, constatou-se que ainda são escassas as pesquisas históricas sobre esse tema, mas são necessárias dada a sua relevância na atualidade, em especial nas políticas públicas de leitura.

Palavras-chave: Biblioteca Escolar. Produção acadêmica. História da Educação.

\begin{abstract}
Aiming to contribute to understanding the Brazilian academic production on school library, we focus in this paper, thesis and dissertations with historical on this subject. Through historical approach, focusing on documentary and bibliographical research and using procedures of locating, recovering, assembling, selecting, ordering documentary sources, we elaborate a research guide, containing academic texts references about school library. From the analysis of academic literature on school library, between 2001 and 2012 years, we observed that there is still little the historical research on this subject, but are necessary because of their relevance today, especially related to public policies on reading.
\end{abstract}

Keywords: School Library. Academic Production. History of Education 
A abordagem histórica na produção acadêmica brasileira sobre biblioteca escolar (2001-2012)

\section{Introdução}

As pesquisas desenvolvidas tanto no campo da Ciência da Informação quanto da Educação ressaltam a importância da biblioteca escolar, considerada por pesquisadores e professores como um espaço em potencial na formação de leitores e como um instrumento na prática pedagógica. Esses benefícios são constantemente reafirmados por diferentes profissionais, dentro e fora da escola, porém ações governamentais em prol da criação e preservação de bibliotecas escolares necessitam, urgentemente, serem efetivadas.

A escola, para muitas crianças brasileiras, é a "[...] porta de entrada para o hábito libertador da leitura [...] ali a leitura, a relação do indivíduo com o precioso objeto livro é socializada" (ALENCAR, 2006, p. 34). Assim, o ideal seria que a biblioteca escolar estivesse integrada com as preocupações da escola e que o bibliotecário auxiliasse nas tomadas de decisões, pois ele é

[...] é aquele em constante questionamento; é aquele que procura conhecer sua área de atuação; é aquele que tem consciência de que o usuário é seu fim último; que sabe que as informações com as quais lida não são neutras e imparciais; que está sempre procurando conhecer os motivos, o que há por trás de suas ações; é aquele que sabe que a informação é imprescindível para a formação do cidadão (ALMEIDA JÚNIOR, 2006, p. 53-54).

Embora constatada a importância da biblioteca escolar, é possível perceber que ela ainda não se constituiu como um espaço privilegiado de leitura e de cultura uma vez que uma sala com um amontoado de livros não se configura como tal. Para além das condições físicas adequadas ao seu funcionamento, faz-se necessária a presença do bibliotecário, profissional capacitado para organizar e tornar o acervo acessível aos alunos, professores e funcionários da escola.

A importância desse profissional foi reafirmada no nível das políticas públicas, com a publicação da lei n ${ }^{\circ} 12.244$ de 24 de maio de $2010^{1}$, conhecida como a Lei da Biblioteca Escolar, a qual exige a contratação de bibliotecários nas escolas públicas e privadas. Essa lei dispõe sobre a universalização das bibliotecas escolares em instituições públicas e privadas no país até o ano de 2020.

De acordo com o artigo $2^{\circ}$ dessa lei, a biblioteca escolar deve ser constituída por uma “[...] coleção de livros, materiais videográficos e documentos registrados em qualquer suporte destinados a consulta, pesquisa, estudo ou leitura" (BRASIL, 2010, p. web). Portanto, não basta

\footnotetext{
${ }^{1}$ Sancionada por Luiz Inácio Lula da Silva, à época presidente do Brasil.
} 
Franciele Ruiz Pasquim

uma prateleira repleta de livros no fundo da sala de aula, é preciso dinamizar as possibilidades da leitura na biblioteca escolar.

Com a publicação dessa lei, foi dado o passo legal rumo à criação de bibliotecas escolares, porém inúmeros são os obstáculos (materiais, físicos e orçamentários) a serem enfrentados pelos responsáveis pela educação. Historicamente, essa situação não foi diferente, pois a criação das primeiras bibliotecas escolares ocorreu nas instituições de formação de professores, marcadas também pela carência de livros e pelo funcionamento precário (VÁLIO, 1990, p.18).

Um exemplo dessas instituições determinantes na formação de professores primários, nas décadas finais do século XIX, foi a Escola Normal de São Paulo, “[...] pólo produtor, propulsor e irradiador das novas idéias pedagógicas, seja mediante o processo de formação teórica e prática- dos novos professores [...]" (MORTATTI, 2000, p. 85). A ênfase dada à formação prática de professores resultou na criação da Escola Modelo primária, onde ocorria a prática de ensino e experimentação dos alunos-mestres da Escola Normal de São Paulo (SOUZA, 1998, p. 40).

De acordo com Mortatti (2000), muitos professores formados na Escola Normal de São Paulo, a fim de responderem às urgências educacionais relativas à diminuição das taxas de analfabetismo e em prol dos ideais republicanos, passaram a escrever cartilhas para alfabetização de crianças.

Dentre esses destaco a atuação de Carlos Alberto Gomes Cardim (1875-1938)² que, em 1925, criou a Biblioteca Infantil do curso primário anexo a essa escola. Para ele, a biblioteca era um instrumento auxiliar para o professor do curso primário, e a leitura era indispensável para a formação do cidadão da República (MORTATTI, 2000; PASQUIM, 2010).

Ainda que Gomes Cardim e seus auxiliares tentassem impulsionar o ensino da leitura por meio da criação dessa biblioteca destinada exclusivamente à infância, “[...] a frequência dos alunos não era obrigatória: os alunos que quisessem podiam pedir livros para estudar ou distrairse”. (JORNAL NOSSO ESFÔRÇO, 1965, n. 8 e 9, p. 7).

\footnotetext{
${ }^{2}$ Carlos Alberto Gomes Cardim nasceu em 10 de fevereiro de 1875, na cidade de São Paulo-SP. Em 1894, aos 19 anos de idade, diplomou-se pela Escola Normal de São Paulo, ano em que iniciou sua carreira no magistério público paulista. Em 1925 foi diretor dessa escola. Foi autor de livros didáticos para o ensino de diferentes disciplinas escolares e autor de artigos publicados em periódicos educacionais no magistério público, tanto no estado de São Paulo quanto no estado do Espírito Santo. Faleceu no dia 2 de junho de 1938, aos 63 anos de idade. (POLIANTÉIA, 1946, p. 105).
} 
A abordagem histórica na produção acadêmica brasileira sobre biblioteca escolar (2001-2012)

Iniciativas como essa já apontavam a biblioteca escolar como um complemento da cultura escolar e como instrumento importante no ensino da leitura. Foi, portanto, no início do regime republicano brasileiro, em que as bases da nação brasileira começaram a serem repensadas, em especial pelas instituições escolares, que se passou a destacar a importância das bibliotecas na formação dos cidadãos da República.

Essas reflexões se relacionam com minha pesquisa de doutorado ${ }^{3}$ em Educação sobre a história das bibliotecas escolares e das bibliotecas infantis no Brasil. O objetivo geral dessa pesquisa é compreender o processo de criação das bibliotecas escolares e das bibliotecas infantis e a constituição de seus acervos de literatura infantil.

Diante do exposto, com objetivo de compreender aspectos da produção de conhecimento acadêmico-científico sobre biblioteca escolar no Brasil e compreender como se configura essa produção em nível de pós-graduação, focalizo, neste artigo, apenas a produção acadêmica sob a forma de dissertações de mestrado e tese de doutorado com abordagem histórica do tema "biblioteca escolar", produzidas entre 2001 e 2012, respectivamente, data do texto mais antigo que localizei e data dos textos mais recentes registrados no Banco de Teses e Dissertações da CAPES (Coordenadoria de Aperfeiçoamento de Pessoal de Nível Superior).

Para tanto, coerentemente com a abordagem histórica proposta, centrada em pesquisa documental e bibliográfica, elaborei um instrumento de pesquisa, o qual resultou no documento Bibliografia sobre biblioteca escolar (PASQUIM, 2015). Nele constam, até o momento, 129 referências de textos ordenadas em seções, por tipo de texto.

A elaboração desse instrumento de pesquisa possibilitou uma importante revisão bibliográfica e contribuiu para visualização de lacunas a serem preenchidas sobre o tema. Outros pesquisadores também se propuseram a fazer um balanço da produção sobre bibliotecas escolares no Brasil, dentre os quais, destaco: Campello (2007) e Aliaga (2013).

Campello (2007) tem por objetivo identificar os assuntos pesquisados, embasamento teórico conceitual, metodologias e técnicas, resultados e conclusões de relatos de pesquisa sobre biblioteca escolar produzidos no Brasil entre 1975 e 2011. Por meio da análise de 70 relatos de

\footnotetext{
${ }^{3}$ Trata-se de pesquisa de doutorado (bolsa CAPES), em andamento, desenvolvida junta ao Programa de PósGraduação em Educação da Faculdade de Filosofia e Ciências, da Universidade Estadual Paulista - UNESP, campus de Marília-SP-Brasil, sob orientação da Profa. Dra. Maria do Rosário Longo Mortatti, e vinculada ao GPHELLB - Grupo de Pesquisa "História do Ensino de Língua e Literatura no Brasil" e ao PIPHELLB - Projeto Integrado de Pesquisa "História do Ensino de Língua e Literatura no Brasil", ambos coordenados pela professora mencionada. O GPHELLB está em funcionamento desde 1994, cadastrado no Diretório dos Grupos de Pesquisa do Brasil - CNPq e certificado pela UNESP.
} 
Franciele Ruiz Pasquim

pesquisa, classificados em seis categorias (biblioteca escolar como espaço de aprendizagem, interação bibliotecário/professor, estudos de usos e usuários, coleção, leitura e pesquisa escolar), Campello (2007) conclui, dentre outros aspectos, que a maioria dessas pesquisas são qualitativas e apresentam referenciais teóricos "frágeis" e pouco claros.

Aliaga (2013) tem por objetivo analisar a biblioteca escolar na produção acadêmica sobre leitura produzida na última década (2000-2010) no Brasil. Por meio da análise de 101 de teses e dissertações de diferentes regiões do Brasil, a autora conclui que a produção sobre biblioteca escolar é muito diversa, porém concentra-se em maior número nos programas de pósgraduação em educação.

Resultados de pesquisas como de Campello (2007) e de Aliaga (2013) contribuem significativamente para o desenvolvimento de pesquisas como essa que venho desenvolvendo, pois possibilitam aos pesquisadores avançar nas reflexões e preencher lacunas nos estudos sobre biblioteca escolar.

\section{Principais características das pesquisas brasileiras sobre biblioteca escolar, com abordagem histórica}

Conforme mencionado, elaborei um instrumento de pesquisa por meio da utilização dos procedimentos de localização, recuperação, reunião, seleção e ordenação de referências de textos sobre biblioteca escolar.

Bellotto (1979, p. 133) destaca a importância da elaboração de instrumentos de pesquisa, uma vez que

[...] constituem-se em vias de acesso do historiador ao documento, sendo a chave da utilização dos arquivos como fontes primárias da História e [...] qualquer que seja a orientação do trabalho histórico a que se proponha um pesquisador, dentro do vastíssimo campo que se abre hoje a História [...] ele necessitará, indubitavelmente, do texto colocado ao seu alcance pelo instrumento de pesquisa (BELLOTTO, 1979, p. 137).

Para a localização de referências de textos sobre biblioteca escolar fiz muitas consultas com termos de busca diferentes em acervos e bases de dados disponíveis on-line, em especial no Banco de Teses e Dissertações da CAPES. Num primeiro momento, os termos de busca utilizados foram: "biblioteca escolar", "história das bibliotecas escolares" e "biblioteca na escola". 
A abordagem histórica na produção acadêmica brasileira sobre biblioteca escolar (2001-2012)

Essas referências, depois de reunidas, foram ordenadas por tipo de texto no documento Bibliografia sobre biblioteca escolar (PASQUIM, 2015). Nele constam, até o momento, 129 referências de textos, ordenadas em seções por tipo de texto, são elas: livros (21); capítulos de livros (2); artigos (18); produção acadêmica (55); notícias em jornais (9); manuais de ensino (10); revistas pedagógicas (5); documentos oficiais (3) e legislação (6). Analisarei, neste artigo, especificamente as dissertações de mestrado e a tese de doutorado com abordagem histórica do tema "biblioteca escolar", produzidas entre 2001 e 2012.

No Quadro 1, apresento a quantidade de dissertações de mestrado e tese de doutorado com abordagem histórica do tema, agrupada por décadas, conforme a data de conclusão de cada trabalho.

\section{Quadro 1 - Quantidade de trabalhos acadêmicos que abordam historicamente a biblioteca escolar, por década}

\begin{tabular}{|c|c|c|c|}
\hline Tipo de texto & $\begin{array}{c}\text { Tese de } \\
\text { doutorado }\end{array}$ & $\begin{array}{c}\text { Dissertações } \\
\text { de mestrado } \\
\text { conclusão do } \\
\text { trabalho }\end{array}$ & $\begin{array}{c}\text { Total } \\
\text { por década }\end{array}$ \\
\hline $2000-2009$ & 1 & 2 & 3 \\
\hline $2010-2011$ & - & 4 & 4 \\
\hline $\begin{array}{c}\text { Total por tipo de } \\
\text { texto }\end{array}$ & - & 6 & 7 \\
\hline
\end{tabular}

Fonte: Bibliografia sobre Bibliotecas Escolares (PASQUIM, 2015)

Conforme os dados sintetizados no quadro acima, embora o tema biblioteca escolar passa a ser pesquisado a partir da década de 1980, a produção acadêmica com abordagem histórica sobre esse tema se iniciou nos anos 2000 em decorrência da ampliação dos programas de pós-graduação no Brasil e do desenvolvimento desse tipo de pesquisa por pesquisadores da Educação, em especial da História da Educação ${ }^{4}$. O primeiro trabalho acadêmico com abordagem histórica do tema "biblioteca escolar" foi desenvolvido na Faculdade de Educação da Universidade Estadual de Campinas (UNICAMP). Trata-se da tese de doutorado em Educação intitulada Programa bibliotecas escolares: memórias/histórias de uma experiência de incentivo à leitura nas escolas municipais de Campinas (1993-2001), defendida por Maria Lúcia Bachiega Kolokathis em 2008.

\footnotetext{
${ }^{4}$ Ver, especialmente, os balanços produzidos no âmbito do GPHELLB: "O I Seminário Internacional sobre história do ensino de leitura e escrita" (MORTATTI, 2011); "50 anos de produção acadêmica brasileira sobre alfabetização: avanços, contradições e desafios" (MORTATTI; OLIVEIRA; PASQUIM, 2014); e "Quatro décadas de produção acadêmica brasileira sobre literatura infantil: avanços, contradições e desafios" (MORTATTI; OLIVEIRA, 2015).
} 
Do conjunto de dissertações de mestrado (6), a maioria (4) foi defendida no âmbito dos programas de pós-graduação em Educação da região Sudeste. As demais foram defendidas em programas de pós-graduação, respectivamente, da região Sul (1) e da região Centroeste (1).

Ainda no conjunto dessa produção, observa-se que as dissertações de mestrado resultantes do desenvolvimento de pesquisa histórica sobre biblioteca escolar foram defendidas em sua maioria nos programas de pós-graduação em Educação (5) e uma dissertação foi defendida no programa de Ciência da Informação (1). Como se pode observar, o tema "biblioteca escolar" com abordagem histórica vem sendo constituído, gradativamente pelo campo da história da educação, contribuindo para a compreensão de velhos problemas relacionados ao seu funcionamento, dentre os quais, destaco: a falta de recursos financeiros; a precariedade dos acervos e as condições físicas inadequadas de funcionamento.

Apresento a seguir resumos analíticos, por ordem cronológica de conclusão, da produção acadêmica brasileira sob a forma de dissertações de mestrado e tese de doutorado com abordagem histórica do tema "biblioteca escolar", produzidas entre 2001 e 2012, data da mais antiga até a mais recente localizada.

Na dissertação de mestrado A biblioteca do Instituto de Educação do Paraná Professor "Erasmo Pilotto": acervo e leitura na formação do conhecimento histórico dos alunos do magistério, Santos (2001) tem por objetivo compreender as práticas de leitura que ocorriam, entre 1940 e 1960, na biblioteca do Instituto de Educação, localizado na cidade de Curitiba (PR). Por meio da análise dos títulos de livros didáticos de história e de estudos sociais, além de entrevista com a bibliotecária desse instituto, a autora conclui que essa biblioteca escolar não foi apenas um espaço de leitura, mas um espaço de prestação de serviços, em especial o empréstimo de livros.

Na tese de doutorado Programa bibliotecas escolares: memórias/histórias de uma experiência de incentivo à leitura nas escolas municipais de Campinas (1993-2001), Kolokathis (2008) tem por objetivo compreender o Projeto Biblioteca foi desenvolvido nas escolas da rede de ensino do município de Campinas (SP) entre 1990 e 2001. Por meio da análise de documentos de professores e alunos que participaram do Projeto Bibliotecas, a autora concluiu que, para além da distribuição de acervos de livros nas escolas, esse projeto contribuiu para a formação continuada de professores no que se referiu à promoção da leitura. 
A abordagem histórica na produção acadêmica brasileira sobre biblioteca escolar (2001-2012)

Na dissertação de mestrado A instituição de bibliotecas nos grupos escolares do estado de São Paulo (1890-1920), Souza (2009) tem por objetivo pesquisar a instituição e as práticas educacionais das bibliotecas nos grupos escolares do Estado de São Paulo, entre 1890 e 1920. Por meio da análise de fontes documentais impressas e manuscritas, encontradas no Arquivo do Estado de São Paulo, tais como, leis, decretos, relatórios, ofícios, anuários, projetos, regulamentações e revistas educacionais, a autora conclui que as bibliotecas dos grupos escolares davam suporte aos professores desde o Império até a primeira década da República.

Na dissertação de mestrado O lugar da biblioteca escolar no discurso da legislação sobre o ensino secundário brasileiro (1838-1968), Assis (2010) tem por objetivo compreender a função educativa da biblioteca escolar no contexto educacional brasileiro, entre 1838 e 1968. Por meio da análise de leis, decretos, decretos-lei, portarias, decisões, cartas, avisos imperiais e exposições, a autora conclui que a biblioteca escolar era destaque nos discursos educativos, porém ela não localizou a “[...] materialidade desses discursos nas escolas [...]” (ASSIS, 2010, p. 103).

$\mathrm{Na}$ dissertação de mestrado Fora de outono certo nem as aspirações amadurecem: Cecília Meireles e a criação da Biblioteca Infantil do Pavilhão Mourisco (1934-1937), Pimenta (2011) tem por objetivo compreender a atuação da escritora Cecília Meireles na divulgação da leitura e do livro infantil à frente da biblioteca pública infantil, localizada no "Pavilhão Mourisco", inaugurada em 1934 na cidade do Rio de Janeiro (RJ). Por meio da análise de fontes documentais, a autora conclui que essa biblioteca dirigida por Cecília Meireles foi um dos projetos da reforma educacional de Anísio Teixeira no Rio de Janeiro.

Na dissertação de mestrado Entre memórias e silêncios: um olhar sobre as bibliotecas do Colégio Pedro II, Dantas (2011) analisa as práticas informacionais dos sujeitos na biblioteca escolar das unidades do Colégio Pedro II, localizado na cidade do Rio de Janeiro (RJ). Por meio da análise de entrevistas feitas com professores, alunos, ex-alunos, bibliotecários e diretores da instituição, Dantas (2011) conclui a existência de um movimento ambíguo entre valorização e desvalorização dos diferentes sentidos atribuídos à biblioteca dessa escola.

Na dissertação de mestrado Uma biblioteca para formação de professores: a biblioteca “Joaquim Nabuco" do Instituto Coração de Jesus, Santo André - SP (1959-1974), Sá (2012) tem por objetivo compreender a circulação de saberes profissionalizantes que se estabeleceram na biblioteca escolar "Joaquim Nabuco", espaço de formação de professores. Por meio da 
análise e identificação de livros que constituíram o acervo dessa biblioteca, a autora conclui que os livros disponíveis na biblioteca se baseavam nos preceitos da Escola Nova.

Deste modo, dentre as principais características metodológicas dessas dissertações de mestrado e da tese de doutorado, destaco que todas tiveram por objetivo compreender a biblioteca escolar como uma instituição excepcionalmente destinada à prática de leitura de alunos e de professores; e utilizaram como fontes documentais, livros, revistas educacionais, jornais, projetos, cartas, avisos imperiais, decretos e regulamentações, além de relatos e entrevistas.

Também foi possível observar que biblioteca escolar é conceituada como um complemento da escola, em especial para a aprendizagem da leitura e das competências do leitor, além de ser considerado um espaço privilegiado para o desenvolvimento das atividades de estudo e de pesquisa. Deste modo, a biblioteca escolar passou a ser um ponto de circulação de saberes indispensáveis para a formação cultural de alunos e professores.

O conjunto dessas pesquisas possibilita compreender aspectos importantes da história das bibliotecas em diferentes momentos históricos, desde o início do século XIX até o final do século XX; e permite constatar a necessidade da efetivação das políticas públicas existentes na criação e preservação desse instrumento valioso na formação de leitores que é a biblioteca escolar.

\section{As principais características da abordagem histórica em Educação}

Como se pode observar nos resumos analíticos das dissertações de mestrado e da tese de doutorado, como ocorre com as pesquisas históricas em educação, "[...] o grande desafio aos pesquisadores interessados em buscar, mediante a compreensão do passado remoto e recente, $o$ enfrentamento dos problemas do presente fugidio e a construção do futuro desejado. (MORTATTI, 1999, p. 75)

A pesquisa de abordagem histórica "[...] demanda a recuperação, reunião, seleção e análise de fontes documentais, como mediadoras na produção de um objeto de investigação" (MORTATTI, 1999, p. 70).

O desenvolvimento desse tipo de pesquisa, portanto, deve se basear em documentos, aqui compreendidos como: 
A abordagem histórica na produção acadêmica brasileira sobre biblioteca escolar (2001-2012)

[...] o resultado de uma montagem, consciente ou inconsciente, da época, da sociedade que o produziram, mas também das épocas sucessivas durante as quais continuou a viver, talvez esquecido, durante as quais continuou a ser manipulado, inda que pelo silêncio. O documento é uma coisa que fica, que dura, o e testemunho, o ensinamento (para evocar a etimologia) que ele traz devem ser em primeiro lugar analisados, desmitificando o seu significado aparente. (LE GOFF, 2003, p. 538)

O olhar para o passado requer do pesquisador a análise da fonte documental que consiste em interrogar os documentos com objetivo de

[...] recuperar totalidade [e] fazer com que o objetivo apareça no emaranhado de suas mediações e contradições; é recuperar como este objeto foi constituído, tentando reconstituir sua razão de ser ou aparecer a nós segundo experiência social, em vez de determiná-lo em classificações e compartimentos fragmentados. (VIEIRA; PEIXOTO E KHOURY, 2002, p. 10-11).

Sobre o desenvolvimento de pesquisas históricas, Vieira, Peixoto e Khoury (2002) destacam "[...] a história como um permanente fazer-se e a investigação histórica como uma busca aberta a múltiplas possibilidades.”. (p.71).

Diante disso, as pesquisas de abordagem histórica acima apresentadas contribuem

[...] tanto para a produção de certa mentalidade histórica e preservacionista quanto para a disponibilização de informações a respeito de seus limites e alcance e, por vezes, para a produção de valiosas obras de referência - guias, catálogos, repertórios, inventários, bibliografias comentadas, "estados da arte", entre outros-, que propiciam a ampliação dos sentidos, usos e funções dos documentos [...] (MORTATTI, 1999, p. 14)

Apesar da importância do desenvolvimento desse tipo de pesquisa, é possível constatar a escassez das pesquisas históricas sobre biblioteca escolar, conforme apontado no tópico anterior, o que talvez se justifique pela falta de preservação ou inexistência das fontes documentais, que são imprescindíveis para o historiador da educação. 


\section{Considerações finais}

Os resultados obtidos, até o momento, contribuem para pensar de forma mais aprofundada sobre as possibilidades de pesquisa, bem como os caminhos a serem percorridos por mim e por outros pesquisadores interessados no estudo do tema.

Em relação ao desenvolvimento de pesquisas históricas sobre biblioteca escolar, foi possível constatar que essa instituição é um lugar de memória e que cabe ao pesquisador compreendê-la em sua complexidade de sentidos, na medida em que o "[...] ontem na sua especificidade e singularidade possibilita alargar o diálogo com o hoje e intensificar a compreensão das questões postas na atualidade" (VIDAL, 2004, p.188).

Ao final deste artigo formulo a seguinte pergunta: em que medida as pesquisas que abordam historicamente a biblioteca escolar têm contribuído para o debate educacional e para as políticas de leitura no Brasil? Talvez, por retomarem o passado, as pesquisas históricas sobre biblioteca escolar podem não ter aplicabilidade direta na resolução dos problemas atuais, porém são indispensáveis na compreensão da importância da permanência das bibliotecas escolares no presente e no futuro. 


\section{Referências}

ALENCAR, C. Um povo de leitores. In: AMORIM, G. (Org.). Políticas públicas do livro e da leitura. São Paulo: Cultura Acadêmica, 2006. p.31-36.

ALIAGA, R. A biblioteca escolar na produção acadêmica sobre leitura: movimentos, diálogos, aproximações. 2013. 218f. Dissertação (Mestrado em Educação) - Faculdade de Educação, Universidade de Campinas, Campinas, 2013.

ALMEIDA JUNIOR, O. Bibliotecário escolar: seu perfil, seu fazer. In: SILVA, R. J.; BORTOLIN, S. (Org.). Fazeres cotidianos na biblioteca escolar. São Paulo: Polis, 2006. p. 44-54.

ASSIS, W. S. O lugar da biblioteca escolar no discurso da legislação sobre o ensino Secundário Brasileiro (1838-1968). 2010. 159f. Dissertação (Mestrado em Educação) Centro de Ciências Humanas e Sociais, Universidade Federal de Mato Grosso do Sul, Campo Grande, 2010.

BELLOTTO, H. L. Os instrumentos de pesquisa no processo historiográfico. In: CONGRESSO BRASILEIRO DE ARQUIVOLOGIA, 4., 1979. Anais... p. 133-147.

BRASIL. Lei da Biblioteca Escolar: Lei no 12.244 de 24 de maio de 2010. Dispõe sobre a universalização das bibliotecas nas instituições de ensino do País. JusBrasil, 2010. Disponível em: <http://presrepublica.jusbrasil.com.br/legislacao/823116/lei-da-bibliotecaescolar-lei-12244-10>. Acesso em: 15 abr. 2014.

CAMPELLO, B. S. et al. Literatura em biblioteca escolar: características de citações de teses e dissertações brasileiras. Transinformação, Campinas, v. 19, n. 3, p. 227-236, set./dez. 2007.

DANTAS, A. G. Entre memórias e silêncios: um olhar sobre as bibliotecas do Colégio Pedro II. Rio de Janeiro, 2011. 126f. Dissertação (Mestrado em Ciência da Informação) Instituto de Arte e Comunicação Social, Universidade Federal Fluminense, Gragoatá, Rio de Janeiro, 2011.

JORNAL O NOSSO ESFORÇO. Órgão do Curso Primário do Instituto de Educação “Caetano de Campos”, n. 8 e 9, ano XXIX. São Paulo, nov./dez. 1965.

KOLOKATHIS, M. L. B. Programa bibliotecas escolares: memórias/histórias de uma experiência de incentivo à leitura nas escolas municipais de Campinas (1993-2001). 2008. 231f. Dissertação (Mestrado em Educação) - Programa de Pós-Graduação em Educação, Universidade Estadual de Campinas, Campinas, 2008.

MORTATTI, M. R. L. Notas sobre linguagem, texto e pesquisa histórica em educação. História da educação, Pelotas, v. 6, p. 69-77, out. 1999.

Os sentidos da alfabetização: São Paulo 1876/1994. São Paulo: Ed. UNESP, 2000.

O I seminário internacional sobre história do ensino de leitura e escrita. In:

(Org.). Alfabetização no Brasil uma história de sua história. São Paulo: Cultura Acadêmica; Marília: Oficina Universitária, 2011. Disponível em: 〈http://www.marilia.unesp.br/Home/Publicacoes/alfabetizacao.pdf>. Acesso em: 
OLIVEIRA, F. R.; PASQUIM, F. R. 50 anos de produção acadêmica brasileira sobre alfabetização: avanços, contradições e desafios. Interfaces da Educação, Paranaíba, v. 5, n. 13, p. 06-31, 2014.

OLIVEIRA, F. R. Quatro décadas de produção acadêmica brasileira sobre literatura infantil: avanços, contradições e desafios. Revista Teias, v. 16, p. 10-32, 2015.

POLIANTÉIA comemorativa do $1^{\circ}$ centenário do Ensino Normal de São Paulo. São Paulo: [s. n], 1946.

LE GOFF, J. História e memória. 5.ed. Campinas: UNICAMP, 2003.

PASQUIM, F. R. P Bibliografia sobre bibliotecas escolares: um instrumento de pesquisa, 2015. (Digitado)

Um estudo sobre cartilha infantil pelo methodo analityco [1910?], de Carlos Alberto Gomes Cardim (1875-1938). 2010. 103f. Trabalho de Conclusão de Curso (Licenciatura em Pedagogia) - Faculdade de Filosofia e Ciências, Universidade Estadual Paulista, Marília, 2010.

PIMENTA, J. Fora de outono certo nem as aspirações amadurecer: Cecília Meireles e a criação da Biblioteca Infantil do Pavilhão Mourisco (1934-1937). Dissertação (Mestrado em Educação) - Departamento de Educação, Pontifícia Universidade Católica, Rio de Janeiro, 2011.

SA, M. G. Uma biblioteca para formação de professores: a Biblioteca "Joaquim Nabuco" do Instituto Coração de Jesus, Santo André (SP) (1959-1974). 2012. 148f. Dissertação (Mestrado em Educação) - Faculdade de Filosofia e Ciências, Universidade Estadual Paulista, Marília, 2012.

SANTOS, R. C. G. P. A biblioteca do Instituto de Educação do Paraná Professor "Erasmo Pilotto": acervo e leitura na formação do conhecimento histórico dos alunos do magistério. Curitiba, 2001. 83 f. Dissertação (Mestrado em Educação). Programa de PósGraduação em Educação, da Universidade Federal do Paraná, Curitiba, 2001.

SOUZA, L. S. A instituição de bibliotecas nos grupos escolares do estado de São Paulo (1890-1920). 2009.110f. Dissertação (Mestrado em Educação) - Faculdade de Educação, da Universidade de São Paulo, São Paulo, 2009.

VÁLIO, E. B. M. Biblioteca escolar: uma visão histórica. Transinformação, Campinas, v.1, p. 15-24, jan./abr. 1990.

VIDAL, D. G. Bibliotecas escolares: experiências escolanovistas nos anos de 1920-1930. In: MENEZES, M. C. Educação, memória, história. Campinas: Mercados das Letras, 2004, p. 187-212.

VIEIRA, M. P. A.; PEIXOTO, M. R. C.; KHOURY, Y. M. A. A pesquisa em história. 4. ed. São Paulo: Ática, 2005. 